\title{
Occult neoplastic cells in the lymph node sinuses and recurrence/metastasis of stage II/Dukes' B colorectal cancer
}

\author{
YASUTOMO SEKIDO ${ }^{1}$, MASAYA MUKAI ${ }^{2}$, KYOKO KISHIMA $^{2}$, TAKAYUKI TAJIMA ${ }^{2}$, \\ TATSUHIKO HOSHIKAWA ${ }^{2}$, MASATO NAKAMURA ${ }^{3}$, NAOYA NAKAMURA ${ }^{4}$ and KYOJI OGOSHI ${ }^{5}$ \\ Departments of ${ }^{1}$ Pathology and ${ }^{2}$ Surgery, Tokai University Hachioji Hospital, 1838 Ishikawa-cho, \\ Hachioji, Tokyo 192-0032; Departments of ${ }^{3}$ Regenerative Medicine, ${ }^{4}$ Pathology and ${ }^{5}$ Surgery, \\ Tokai University School of Medicine, Bohseidai, Isehara, Kanagawa 259-1193, Japan
}

Received June 24, 2010; Accepted September 3, 2010

DOI: 10.3892/or_00001043

\begin{abstract}
Lymph nodes from patients with colorectal cancer were immunohistochemically stained for cytokeratin in order to investigate the relationship between the presence of occult neoplastic cells (ONCs) and recurrence/metastasis. A total of 78 patients with stage II/Dukes' B colorectal cancer were divided into two groups. The first group consisted of 18 patients who had developed recurrence/metastasis (recurrence group) and the other one of 60 patients who had survived without recurrence (non-recurrence group). The presence of ONCs was compared between the two groups with respect to i) single cells ( $\geq 3$ floating ONCs), ii) clusters of cells $(\geq 1$ floating aggregates of 2-20 ONCs), and iii) single cells + clusters. When single cells were detected, the sensitivity for recurrence was $55.6 \%(10 / 18)$, the positive predictive value (PPV) was $30.3 \%$ (10/33), the specificity was $61.7 \%$ (37/60, $\mathrm{p}=0.195$ ), and the negative predictive value (NPV) was $82.2 \%$ (37/45). For the clusters, the sensitivity was $55.6 \%$ (10/18), PPV was $37 \%(10 / 27)$, specificity was $71.7 \%$ (43/60, $\mathrm{p}=0.033)$, and NPV was $84.3 \%$ (43/51). With single cells + clusters, the values were $55.6 \%(10 / 18), 43.5 \%(10 / 23)$, $78.3 \%(47 / 60, \mathrm{p}=0.006)$, and $85.5 \%$ (47/55), respectively. These results suggest that the detection of single cells + clusters has a high specificity and NPV, and indicates a low risk of recurrence/metastasis in patients with stage II colorectal cancer.
\end{abstract}

Correspondence to: Dr Yasutomo Sekido, Department of Pathology, Tokai University Hachioji Hospital, 1838 Ishikawa-cho, Hachioji, Tokyo 192-0032, Japan

E-mail: sekido.yasutomo@hachioji-hosp.tokai.ac.jp

Abbreviations: ONCs; occult neoplastic cells, PPV, positive predictive value; NPV, negative predictive value; FP, false positive; $\mathrm{FN}$, false negative

Key words: colorectal cancer, occult neoplastic cells, high-risk group, recurrence/metastasis, stage II, Dukes' B, isolated tumor cells

\section{Introduction}

The prognosis of primary colorectal cancer has improved markedly in Japan due to progress in chemotherapy and radiotherapy as well as surgical techniques. The 5-year survival rate of patients who have stage II/Dukes' B colorectal cancer without lymph node metastasis and who undergo curative resection, is reported to be between 80 and $85 \%$ (colon, $84.5 \pm 2.8 \%$; rectum, $79.8 \pm 4.0 \%)(1-4)$. However, this means that distant metastasis or recurrence occurs in 15 to $20 \%$ of patients who undergo curative resection and this can influence survival $(2,4)$. Hematogenous metastasis to the liver or the lungs in patients without lymph node metastasis and who have undergone curative resection, is presumed to occur when cancer cells circulating through the blood during the perioperative period, escape the immune system, enter the microcirculation of the liver or the lungs, and find an ideal microenvironment for growth and proliferation (5-8). Many studies have been published on the close relationship between the recurrence/metastasis of cancer and the detection of occult neoplastic cells (ONCs) by cytokeratin immunohistochemical staining in the sinuses of lymph nodes distant from the primary tumor (9-13). ONCs can be semi-quantitatively assessed by relatively simple immunostaining and represent floating malignant tumor cells trapped in the lymph nodes, which are part of the host immune system $(5,6)$. These cells are observed in $\sim 70$ to $80 \%$ of the patients with recurrence of stage III/ Dukes' $\mathrm{C}$ colorectal cancer, whereas the incidence is lower ( 20 to $30 \%)$ in patients with recurrent stage II/Dukes' B colorectal cancer $(7,8)$. ONCs can be classified as single cells, ONC clusters ( $\leq 10$ cells with a diameter of $\sim 0.2 \mathrm{~mm}$ ), and ONC aggregates with $>10$ cells. It has been reported that ONCs should be considered as highly malignant occult systemic metastases, and should be clearly distinguished from isolated tumor cells $(\leq 0.2 \mathrm{~mm})$ and micrometastases $(0.2$ to $\leq 2 \mathrm{~mm}$ ), which form very small metastatic foci in the lymph nodes (14-16). Susceptibility to anti-cancer agents and the optimal dosage/administration schedule are also factors to consider, although cancer cells remaining in the microcirculation should be eradicated by adjuvant chemotherapy early after surgery. If it was possible to identify a high-risk group for recurrence/metastasis among patients with stage II/ 
Dukes' B colorectal cancer, survival could be improved by the administration of adjuvant chemotherapy, which is usually given to patients with stage III/Dukes' $\mathrm{C}$ cancer in the early post-operative period. In addition, identifying a low-risk group of patients who are not likely to develop recurrence/ metastasis, would contribute to reducing the psychological burden on patients and to devising appropriate follow-up plans.

Cytokeratin is an epithelial marker that is useful for the detection of micrometastasis to the lymph nodes, as $>99 \%$ of normal lymph nodes are not stained, and AE1/AE3 and CAM 5.2 are well-known anti-cytokeratin antibodies (17-21). As cancer cells can be examined to assess their nuclear structure and cytoplasm, histological and immunohistochemical studies are superior to tests such as PCR in terms of assessing the viability and proliferative capacity of each cell $(17,18)$. A detailed clinicopathological examination of the clinical course and subclassification of ONCs into single cells or clusters in patients with stage II colorectal cancer, has not been reported so far. Accordingly, the purpose of this study was to investigate the presence of various types of ONCs by cytokeratin immunostaining of the lymph nodes in surgically resected specimens of patients with stage II/Dukes' B colorectal cancer.

\section{Patients and methods}

Among 86 patients with stage II/Dukes' B colorectal cancer for whom complete medical records were available and follow-up had been performed between January 2005 and January 2010, 78 patients were enrolled in this study from whom $>15$ lymph nodes were retrieved (15). Of these 78 patients, recurrence/metastasis occurred within three years in 18 patients (recurrence group) (23.1\%), whereas 60 patients had no recurrence (non-recurrence group) (76.9\%). The dissected lymph nodes obtained from these two groups were
Table I. Detection of ONCs in lymph node sinuses (single cells) in the two groups.

\begin{tabular}{|c|c|c|}
\hline $\begin{array}{l}\text { Total } 78 \text { cases } \\
(\text { Efficiency } 60.3 \%)\end{array}$ & $\begin{array}{l}\text { Recurrence } \\
\text { group }(n=18)\end{array}$ & $\begin{array}{l}\text { Non-recurrence } \\
\text { group }(n=60)\end{array}$ \\
\hline $\begin{array}{l}\text { Single cells }(+) \\
33 \text { cases } \\
(\text { PPV } 30.3 \%)\end{array}$ & $\begin{array}{l}10 \text { cases } \\
\text { (Sensitivity } 55.6 \% \text { ) }\end{array}$ & $\begin{array}{l}23 \text { cases } \\
(\text { FP rate } 38.3 \%)\end{array}$ \\
\hline $\begin{array}{l}\text { Single cells (-) } \\
45 \text { cases } \\
(\mathrm{NPV} 82.2 \%)\end{array}$ & $\begin{array}{l}8 \text { cases } \\
(\mathrm{FN} \text { rate } 44.4 \%)\end{array}$ & $\begin{array}{l}37 \text { cases }^{\mathrm{a}} \\
\text { (Specificity } \\
61.7 \%)\end{array}$ \\
\hline
\end{tabular}

${ }^{\mathrm{a}} \mathrm{p}=0.195$. Hazard ratio 0.848 (95\% CI; 0.652-1.102).

immunohistochemically stained for cytokeratin in order to compare the detection of ONCs with the clinical course.

The routine indirect immunoperoxidase method was used for cytokeratin staining of the lymph nodes $(17,18)$. Thin sections $(3 \mu \mathrm{m})$ were prepared from the largest cut surface of each formalin-fixed and paraffin-embedded lymph node. After deparaffinization, the sections were immunostained by an autoanalyzer (BenchMark ${ }^{\circledR}$ XT; Roche Diagnostics K.K., Tokyo, Japan). After enzymatic treatment with protease 1 (Roche Diagnostics K.K.) (0.5 units $/ \mathrm{ml}$ ) for $4 \mathrm{~min}$ at $37^{\circ} \mathrm{C}$ to activate the antigen, monoclonal anti-cytokeratin antibodies (AE1, AE3, or PCK26; Roche Diagnostics K.K.) were used as the primary antibody, and the iVIEW DAB Detection kit (Roche Diagnostics K.K.) was used as an auto-immunostaining reagent. Dehydration and mounting were performed after nuclear staining with hematoxylin.

H\&E staining and cytokeratin immunostaining were performed for serial sections of each lymph node in order to

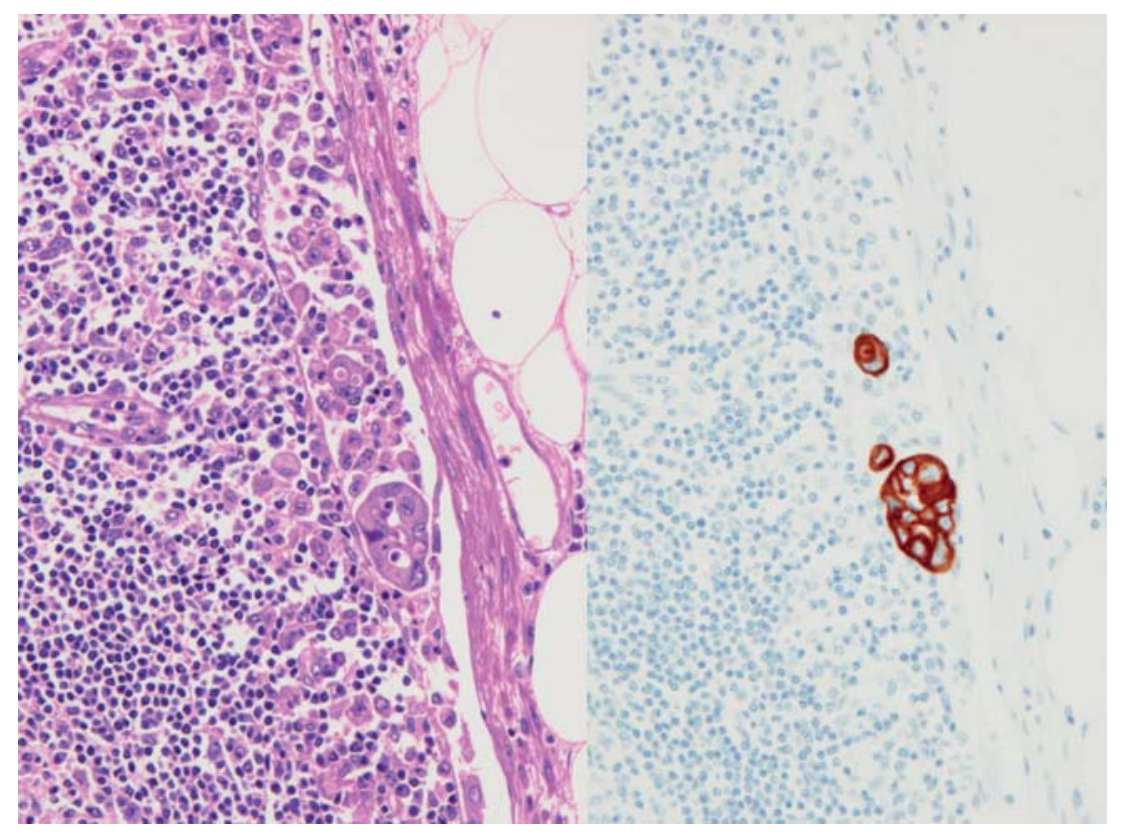

Figure 1. ONCs floating in lymph node sinuses detected by cytokeratin immunohistochemistry and classified as single cells + clusters. 
Table II. Detection of ONCs in lymph node sinuses (clusters) in the two groups.

\begin{tabular}{|c|c|c|}
\hline $\begin{array}{l}\text { Total } 78 \text { cases } \\
\text { (Efficiency } 67.9 \% \text { ) }\end{array}$ & $\begin{array}{l}\text { Recurrence } \\
\text { group }(n=18)\end{array}$ & $\begin{array}{l}\text { Non-recurrence } \\
\text { group }(n=60)\end{array}$ \\
\hline $\begin{array}{l}\text { Clusters (+) } \\
27 \text { cases } \\
(\text { PPV 37\%) }\end{array}$ & $\begin{array}{l}10 \text { cases } \\
\text { (Sensitivity } 55.6 \%)\end{array}$ & $\begin{array}{l}17 \text { cases } \\
(\mathrm{FP} \text { rate } 28.3 \%)\end{array}$ \\
\hline $\begin{array}{l}\text { Clusters }(-) \\
51 \text { cases } \\
(\text { NPV } 84.3 \%)\end{array}$ & $\begin{array}{l}8 \text { cases } \\
\text { (FN rate } 44.4 \%)\end{array}$ & $\begin{array}{l}43 \text { cases }^{\mathrm{a}} \\
\text { (Specificity } \\
71.7 \%)\end{array}$ \\
\hline
\end{tabular}

${ }^{\mathrm{a}} \mathrm{p}=0.033$. Hazard ratio 0.747 (95\% CI; 0.546-1 .021).

Table III. Detection of ONCs in lymph node sinuses (single cells + clusters) in the two groups.

\begin{tabular}{|c|c|c|}
\hline $\begin{array}{l}\text { Total } 78 \text { cases } \\
\text { (Efficiency } 60.3 \% \text { ) }\end{array}$ & $\begin{array}{l}\text { Recurrence } \\
\text { group }(n=18)\end{array}$ & $\begin{array}{l}\text { Non-recurrence } \\
\text { group }(n=60)\end{array}$ \\
\hline $\begin{array}{l}\text { Single cells }+ \\
\text { clusters }(+) \\
23 \text { cases } \\
(\text { PPV } 43.5 \%)\end{array}$ & $\begin{array}{l}10 \text { cases } \\
\text { (Sensitivity } 55.6 \%)\end{array}$ & $\begin{array}{l}23 \text { cases } \\
(\text { FP rate } 21.7 \%)\end{array}$ \\
\hline $\begin{array}{l}\text { Single cells + } \\
\text { clusters (-) } \\
55 \text { cases } \\
(\mathrm{NPV} 85.5 \%)\end{array}$ & $\begin{array}{l}8 \text { cases } \\
(\mathrm{FN} \text { rate } 44.4 \%)\end{array}$ & $\begin{array}{l}47 \text { cases }^{\mathrm{a}} \\
\text { (Specificity } \\
78.3 \% \text { ) }\end{array}$ \\
\hline
\end{tabular}

${ }^{\mathrm{a}} \mathrm{p}=0.006$. Hazard ratio 0.661 (95\% CI; 0.455-0.962).

detect positive cells. After excluding cancer cells and/or cancer nests associated with fibrosis in the lymph nodes, immunostained cells floating in the lymph node sinuses were identified (5-8). Separately identifiable tumor cells were defined as single cells, while 2-20 tumor cells forming a small aggregate $(\leq 0.2 \mathrm{~mm})$ were defined as a cluster. Then ONCs were classified as i) single cells ( $\geq 3$ ONCs), ii) clusters of cells ( $\geq 1$ floating aggregates of $2-20 \mathrm{ONCs}$ ), or iii) single cells + clusters (Fig. 1). Cells satisfying all of the above conditions were judged to be positive and other cells were classified as negative. Then the sensitivity, false positive (FP) rate, specificity, false negative (FN) rate, positive predictive value (PPV), negative predictive value (NPV) and efficiency, were calculated for each type of ONC. Histopathological diagnosis was performed by Y.S., who had no knowledge of the clinical background of the patients, while M.M. and K.K. performed data collection and analysis.

Statistical analysis. The $\chi^{2}$ test was used to compare the recurrence with the non-recurrence group and the risk ratios
(95\% CI) were calculated. A p-value of $<0.05$ was considered to indicate significance in all the analyses. SPSS statistics software version 17 (SPSS Japan Inc., Tokyo, Japan) was employed.

\section{Results}

Single cells ( $\geq 3$ ONCs). When single cells were detected, the sensitivity for the prediction of recurrence/metastasis was $55.6 \%(10 / 18)$, while the FP rate was $38.3 \%(23 / 60)$, the specificity was $61.7 \%(37 / 60, \mathrm{p}=0.195$, hazard ratio 0.848 , 95\% CI; 0.652-1.102), and the FN rate was $44.4 \%$ (8/18). In addition, the PPV was $30.3 \%$ (10/33), NPV was $82.2 \%$ $(37 / 45)$, and efficiency was $60.3 \%$ (Table I).

Clusters ( $\geq 1$ floating aggregates of 2-20 ONCs). For clusters, the sensitivity was $55.6 \%(10 / 18)$, the FP rate was $28.3 \%$ $(17 / 60)$, the specificity was $71.7 \%(43 / 60, \mathrm{p}=0.033$, hazard ratio $0.747,95 \% \mathrm{CI}$; $0.546-1.021)$, the $\mathrm{FN}$ rate was $44.4 \%$ (8/18 cases), PPV was $37.0 \%(10 / 27)$, NPV was $84.3 \%$ (43/51), and efficiency was $67.9 \%$ (Table II).

Single cells + clusters. For single cells + clusters, the sensitivity was $55.6 \%(10 / 18)$, while the FP rate was $21.7 \%(13 / 60)$, specificity was $78.3 \%(47 / 60, \mathrm{p}=0.006$, hazard ratio 0.661 , 95\% CI; 0.455-0.962), the FN rate was $44.4 \%$ (8/18), PPV was $43.5 \%$ (10/23), NPV was $85.5 \%$ (47/55), and efficiency was $73.1 \%$ (Table III).

\section{Discussion}

It has been reported that D2 lymph node dissection during surgery for primary colorectal cancer, contributes to the survival of patients with stage II/Dukes' B colorectal cancer, but not to that of patients with stage III/Dukes' C colorectal cancer (22). The purpose of lymph node dissection is to achieve the complete en bloc removal of metastatic lymph nodes, and it also contributes to the standardization of the method for determining true node negativity by collecting a large number of lymph nodes including those without metastasis from specific sites (23). Identification of at least 12 lymph nodes is also recommended in the NCI guidelines for diagnosing true node negativity, and the factor that is important for prognosis is considered to be the number of metastatic foci observed in lymph nodes retrieved by D2 resection $(23,24)$.

Post-operative adjuvant chemotherapy is recommended in the Japanese guidelines for patients with a high risk of recurrence as well as among those with stage II/Dukes' B colorectal cancer without lymph node metastasis. However, criteria for their selection, other than the infiltration of other organs (TNM classification; T4), budding at the deepest part of the primary tumor, and the presence or absence of vascular involvement $(2,4)$, have not yet been provided. N0 without lymph node metastasis implies a localized tumor and distant metastasis/recurrence is not observed in $80-85 \%$ of these patients, who are therefore considered to be a low-risk recurrence group. It is thought that a very small number of tumor cells enter the portal circulation of patients with stage II/NO tumors. In addition, non-specific host immunity has 
been reported to be stronger in stage II compared to stage III patients, who have systemic disease (25-29). Particularly, a biological response could be activated by the single cells, inducing tumor immunity, but potent post-operative adjuvant chemotherapy, similar to that used for stage III/Dukes' C cancer patients, is still necessary for $\sim 15-20 \%$ of patients who have a higher risk of recurrence/metastasis, including those with ONC clusters $(8,28,30)$. The results of this study suggest that the detection of single cells + clusters was a useful negative indicator in patients with ONCs (high specificity/ high NPV). However, it is not directly related to recurrence/ metastasis and many factors such as host immunity and tumor susceptibility to anti-cancer agents, are also involved. A clinical indicator with a high sensitivity and PPV should be investigated in the future in order to accurately identify the group with a high risk of recurrence/matastasis among patients with stage II/Dukes' B colorectal cancer, which is N0 localized cancer.

The relationship between single tumor cells in the lymph nodes and recurrence/metastasis has not yet been clarified. This is possibly due to the fact that ONCs with poor viability become trapped in the lymph node sinuses and are still detectable, even though such cells are not involved in recurrence/metastasis $(5,6)$. Single cells are usually eradicated by the host immune response however numerous they are, and do not cause recurrence, whereas clusters consisting of several to a dozen ONCs cannot be destroyed by the host defenses and can proliferate to form micrometastases. We therefore investigated the occurrence of ONC clusters consisting of 2-20 tumor cells, the viability of which can be easily judged in comparison to the conventional assessment of single cells. Clusters are thought to be either spheres $\leq 0.2 \mathrm{~mm}$ in diameter, or structures with the appearance of a bunch of grapes. However, it is not known at present whether there is interstitial material connecting the individual cancer cells, or whether clusters contain cancer stem cells with resistance to anti-cancer agents that transmit important information for tumor survival $(16,28,30)$. Although clusters are considered easier compared to single cells, for the assessment of the proliferative capacity based on the nuclear structure, cytoplasmic morphology and staining, relatively few clusters (1-3) were found in the patients with stage II/N0 localized tumors (data not shown). As there was no significant difference in metastasis observed in the single cells, and it was observed in the clusters of cells, a certain number of clusters could be required for tumor cells to survive the host defenses in the microcirculation and create distant metastasis/recurrence. A more detailed clinicopathological investigation, including the assessment of the number of clusters and susceptibility to anti-cancer agents, should be performed in the future on a larger number of patients.

\section{Acknowledgements}

This study was supported by grants from the Occult Neoplastic Cells Research and Study Group (no. 2009-3049; Tokai University Hachioji Hospital, Tokyo, Japan) and the Research and Study Program of Tokai University Educational System General Research Organization (no. 2007-04; Tokai University School of Medicine, Kanagawa, Japan).

\section{References}

1. Japanese Society for Cancer of the Colon and Rectum: MultiInstitutional Registry of Large Bowel Cancer in Japan. Cases treated in 1994. Vol. 23. Tokyo, 2002.

2. Makuuchi M and Sugihara K: Knacks and Pitfalls. In: Surgery of the Colon, Rectum and Anus. 2nd edition. Bunkoudou Co., Ltd., Tokyo, 2004.

3. Japanese Society for Cancer of the Colon and Rectum: General Rules for Clinical and Pathological Studies on Cancer of the Colon, Rectum and Anus. 7th edition. Kanehara \& Co., Ltd., Tokyo, 2006.

4. Japanese Society for Cancer of the Colon and Rectum: Guidelines for Large Bowel Cancer in Japan. Tokyo, 2009.

5. Mukai M, Sato S, Komatsu N, Nishida T, Shiba K, Ito I, Nakasaki H and Makuuchi H: Correlation between occult neoplastic cells in the lymph node sinuses and recurrence in patients with Dukes' C colorectal cancer. Oncol Rep 10: 1165-1169, 2003.

6. Mukai M, Sato S, Komatsu N, Nishida T, Shiba K, Ito I, Nakasaki $\mathrm{H}$ and Makuuchi $\mathrm{H}$ : Correlation between occult neoplastic cells in the lymph node sinuses and recurrence in patients with curatively resected Dukes' B colorectal cancer. Oncol Rep 10: 1177-1181, 2003.

7. Mukai M, Sato S, Tajima T, Kimura T, Komatsu N, Ninomiya H, Nakasaki H, Ogoshi K and Makuuchi H: Predicting recurrence and metastasis of stage II/Dukes' B colorectal cancer without lymph node metastasis. Oncol Rep 12: 1127-1130, 2004.

8. Mukai M, Sato S, Tajima T, Kimura T, Komatsu N, Ninomiya H, Nakasaki H, Ogoshi K and Makuuchi $\mathrm{H}$ : Predicting recurrence and metastasis of stage III/Dukes' C colorectal cancer with lymph node metastasis. Oncol Rep 12: 1301-1304, 2004.

9. Mukai M, Sato S, Nakasaki H, Saito Y, Nishiumi N, Iwasaki M, Tokuda Y, Ogoshi K, Inoue H and Makuuchi H: Occult neoplastic cells in the lymph node sinuses and recurrence of primary breast, lung, esophageal and gastric cancer. Oncol Rep 11: 81-84, 2004.

10. Mukai M, Sato S, Komatsu N, Kimura T, Ninomiya H, Nakasaki H, Ogoshi K and Makuuchi M: Accuracy of criteria for predicting the recurrence and metastasis of stage I and II gastric cancer without lymph node metastasis. Oncol Rep 12: 59-62, 2004.

11. Mukai M, Sato S, Komatsu N, Kimura T, Ninomiya H, Nakasaki H, Ogoshi K and Makuuchi H: Accuracy of criteria for predicting recurrence and metastasis in stage II and III gastric cancer with lymph node metastasis. Oncol Rep 12: 63-66, 2004.

12. Mukai M, Sato S, Komatsu N, Kimura T, Ninomiya H, Nakasaki H, Ogoshi K and Makuuchi H: Predicting the recurrence/metastasis of stage II and III breast cancer with lymph node metastasis. Oncol Rep 12: 303-306, 2004.

13. Mukai M, Sato S, Komatsu N, Kimura T, Ninomiya H, Nakasaki H, Ogoshi K and Makuuchi H: Predicting the recurrence/metastasis of stage I and II breast cancer without lymph node metastasis. Oncol Rep 12: 745-748, 2004.

14. TNM classification of malignant tumours. 6th edition. John Wiley \& Sons, Inc., New York, 2002.

15. Mukai M, Sato S, Nishida T, Komatsu N, Shiba K, Nakasaki H and Makuuchi H: Selection criteria for high risk and low risk groups of recurrence and metastasis in patients with primary colorectal cancer. Oncol Rep 10: 1753-1758, 2003.

16. Mukai M: Occult neoplastic cells and malignant microaggregates in lymph node sinuses: Review and hypothesis. Oncol Rep 14: 173-175, 2005.

17. Nakane PK and Pierce GB: Enzyme-labeled antibodies: preparation and application for localization of antigens. $\mathrm{J}$ Histochem Cytochem 14: 929-931, 1966.

18. Nakane PK and Pierce GB: Enzyme-labeled antibody for the light and electron microscopic localization of tissue antigens. J Cell Biol 33: 307-318, 1967.

19. Greenson JK, Isenhart CE, Rice R, Mojzisik C, Houchens D and Martin EW: Identification of occult micrometastases in pericolic lymph nodes of Dukes' B colorectal cancer patients using monoclonal antibodies against cytokeratin and CC49. Cancer 73: 563-569, 1994.

20. Nicholson AG, Marks CG and Cook MG: Effect on lymph node status of triple leveling and immunohistochemistry with CAM 5.2 on node negative colorectal carcinomnas. Gut 35: 1447-1448, 1994.

21. Isaka N, Nozue M, Doy M and Fukao K: Prognostic significance of perirectal lymph node micrometastases in Dukes' B rectal carcinoma: an immunohistochemical study by CAM 5.2. Clin Cancer Res 5: 2065-2068, 1999. 
22. Prandi M, Lionetto R, Bini A, Francioni G, Accarpio G, Anfossi A, Ballario E, Bacchi G, Bonilauri S, Carobbi A Cavaliere P, Garcea D, Giuliani L, Morziani E, Mosca F, Mussa A, Pasqualini M, Poddie D, Tonetti F, Zardo L and Rosso R: Prognostic evaluation of stage B colon cancer patients is improved by an adequate lymphadenectomy. Ann Surg 235 458-463, 2002

23. Mukai M, Ito I, Mukoyama S, Tajima T, Saito Y, Nakasaki H, Sato $\mathrm{S}$ and Makuuchi H: Improvement of 10 -year survival by Japanese radical lymph node dissection in patients with Dukes' B and C colorectal cancer: A 17-year retrospective study. Oncol Rep 10: 927-934, 2003

24. Nelson H, Petrelli N, Carlin A, Couture J, Fleshman J, Guillem J, Miedema B, Ota D and Sargent D: Guidelines 2000 for colon and rectal cancer surgery. J Natl Cancer Inst 93: 583-596, 2001.

25. Mitomi T, Tsuchiya S, Iijima N, Aso K, Suzuki K, Nishiyama K, Amano T, Takahashi T, Murayama N, Oka H, Oya K, Noto T and Ogawa N: Randomized controlled study on adjuvant immnochemotherapy with PSK in curatively resected colorectal cancer. The Cooperative Study Group of Surgical Adjuvant Immunochemotherapy for Cancer of the Colon and Rectum (Kanagawa). Dis Colon Rectum 35: 123-130, 1992.
26. Mukai M, Tajima T, Nakasaki H, Sato S, Ogoshi K and Makuuchi H: Efficacy of postoperative adjuvant oral immunochemotherapy in patients with Dukes' B colorectal cancer. Ann Cancer Res Ther 11: 201-214, 2003.

27. Mukai M, Tajima T, Nakasaki H, Sato S, Ogoshi K and Makuuchi H: Efficacy of postoperative adjuvant oral immunochemotherapy in patients with Dukes' C colorectal cancer. Ann Cancer Res Ther 11: 215-229, 2003.

28. Ito I, Mukai M, Ninomiya H, Kishima K, Tsuchiya K, Tajima T, Oida Y, Nakamura M and Makuuchi H: Comparison between intravenous and oral postoperative adjuvant immunochemotherapy in patients with stage II colorectal cancer. Oncol Rep 20: 1189-1194, 2008.

29. Ito I, Mukai M, Ninomiya H, Kishima K, Tsuchiya K, Tajima T, Oida Y, Nakamura M and Makuuchi H: Comparison between intravenous and oral postoperative adjuvant immunochemotherapy in patients with stage III colorectal cancer. Oncol Rep 20: 1521-1526, 2008.

30. Mukai M, Ninomiya H, Kishima K, Tsuchiya K, Tajima T, Ito I, Nakamura M and Makuuchi M: Efficacy of 5FU/LV plus CPT-11 as the first-line postoperative adjuvant chemotherapy in patients with stage IIIa colorectal cancer. Oncol Rep 22: 621-629, 2009. 